\title{
Two-Year Clinical Evaluation of Resinous Restorative Systems in Non-Carious Cervical Lesions
}

\author{
Sérgio Lima SANTIAGO ${ }^{1}$ \\ Vanara Florêncio PASSOS ${ }^{1}$ \\ Alessandra Helen Magacho VIEIRA ${ }^{1}$ \\ Maria Fidela de Lima NAVARRO2 \\ José Roberto Pereira LAURIS ${ }^{2}$ \\ Eduardo Batista FRANCO ${ }^{2}$ \\ ${ }^{1}$ Federal University of Ceará, Fortaleza, CE, Brazil \\ ${ }^{2}$ Bauru Dental School, University of São Paulo, Bauru, SP, Brazil
}

\begin{abstract}
This controlled clinical trial evaluated the 2-year clinical performance of a one-bottle etch-and-rinse adhesive and resin composite system (Excite/Tetric Ceram) compared to a resin-modified glass ionomer cement (RMGIC) (Vitremer/3M) in non-carious cervical lesions. Seventy cervical restorations ( 35 resin composite - RC- restorations and 35 RMGIC restorations) were placed by a single operator in 30 patients under rubber dam isolation without mechanical preparation. All restorations were evaluated blindly by 2 independent examiners using the modified USPHS criteria at baseline, and after 6, 12 and 24 months. Data were analyzed statistically by Fisher's exact and McNemar tests. After 2 years, 59 out of 70 restorations were evaluated. As much as $78.8 \%$ retention rate was recorded for RC restorations, while $100 \%$ retention was obtained for RMGIC restorations. Fisher's exact test showed significant differences $(\mathrm{p}=0.011)$ for retention. However, there were no significant differences for marginal integrity, marginal discoloration, anatomic form and secondary caries between the RC and RMGIC restorations. The McNemar test detected significant differences for Excite/TC between baseline and the 2-year recall for retention $(p=0.02)$, marginal integrity $(p=0.002)$ and anatomic form $(p=0.04)$. Therefore, the one-bottle etch-and-rinse bonding system/resin composite showed an inferior clinical performance compared to the RMGIC.
\end{abstract}

Key Words: Resin composite, resin modified glass ionomer, clinical trial, cervical lesion.

\section{INTRODUCTION}

The clinical management of non-carious cervical lesions (NCCL) is a challenge concerning restoring procedures because, most of the time, the cervical margin of these lesions is located in cementum or dentin (1). This characteristic makes the cervical margin more susceptible to microleakage, causing cavosurface stains and postoperative sensitivity (2). Moreover, the in NCCL is usually sclerotic or vitrified (2). It determines lower adhesive quality than the one of non-sclerotic due to the different pattern of acid etching in highly mineralized tissue (3).

Different restorative materials and techniques have been proposed for non-carious cervical lesion treatment what reflects the difficulty of this challenge $(4,5)$. Current materials that avoid excessive removal of sound tooth structure, such as resin composite and glass ionomer cement, for esthetic and functional reasons, are widely used for restoring cervical areas (4).

Resin composites and adhesives systems are being continually developed with the purpose of improving retention to the dental structure and simplifying clinical procedures (1). One-bottle adhesives have emerged as an option to reduce operative steps of adhesive aesthetic restorations (2). Nevertheless, some problems have been identified with this category of adhesive system, including permeability and hydrolysis $(2,3)$.

Improvement of the properties of conventional glass ionomer cement (GIC) originated hybrid materials 
classified as resin-modified GICs (RMGICs) (6). The addition of light-cured resin components resulted in higher mechanical characteristics and higher resistance to early moisture contact and desiccation (7). Furthermore, RMGICs are less technique sensitive and have improved bond strength to tooth structure (6).

Numerous studies have evaluated the clinical performance of resin composites and GICs in NCCL. In general, retention rates for resin composite restorations are markedly lower when compared to glass ionomer restorations $(7,8)$. According to Neo et al. (8), the GIC continues to be the most retentive material for NCCL.

This study was designed to evaluate the 2-year clinical performance of a one-bottle etch-and-rinse bonding system associated with a hybrid resin composite compared to a RMGIC in NCCL, following the modified United States Public Health Service (USPHS) categories and criteria. The hypothesis tested was that both materials have acceptable effectiveness after 2 years of clinical service.

\section{MATERIAL AND METHODS}

\section{Patient Selection}

Thirty volunteer patients with ages ranging between 18 and 50 years participated in this study. The volunteers were instructed on the conditions and objective of the study, and they signed informed consent forms and authorizations to participate in this investigation, which had been reviewed and approved by the Research Ethics Committee of Bauru Dental School. The inclusion criteria were: good oral hygiene, low decay index, no periodontal disease or deleterious habits, no wear facets and the presence of at least two NCCL. All lesions were no less than $1 \mathrm{~mm}$ deep and independent of their location in the dental arch. A total of 70 NCCL were restored using the materials shown in Table 1. For each subject, at least two different restorations were placed in a random basis. Seventy percent of the restorations were located in the upper arch and 30\% in the lower arch. Eighty percent of them were placed in premolars, $10 \%$ in molars and $10 \%$ in anterior teeth.

The sample size of 30 patients, the number of restorations (35 per material), and the distribution of restorations (maximum of 3 pairs in the same patient) are in accordance to the American Dental Association guidelines for testing a new material (9).

\section{Restorative Procedures}

Restorative procedures were carried out by a single operator. All restorations ( 35 for each material) were placed under rubber dam isolation, and the cavities were pumiced prior to restoration intervention. Enamel margins were not beveled, and no mechanical retention was performed. Twenty-six patients received 2 restorations, 3 patients received 4 restorations and 1 patient received 6 restorations. The distribution of materials to the tooth groups was as follows: 4 maxillary anterior, 22 maxillary posterior and 9 mandibular posterior teeth received. Resin composite restorations; 3 maxillary anterior, 24 maxillary posterior and 8 mandibular posterior teeth received RMGIC restorations.

Half of the cavities were restored with a onebottle etch-and-rinse adhesive and resin composite system (Excite/Tetric Ceram; Ivoclar Vivadent, Schaan, Liechtenstein) and the other half with the RMGIC (Vitremer, 3M ESPE, St. Paul, MN, USA), according to the manufacturer's instructions, as follows.

Excite/Tetric Ceram: Enamel and dentin were etched for 30 and 15 s, respectively, with $37 \%$ phosphoric acid gel (Total Etch; Ivoclar Vivadent) and rinsed with water spray. Dentin was blotted with absorbent paper to keep the surface moist. One coat of Excite was applied and gently brushed for $10 \mathrm{~s}$. An air

Table 1. Composition of the studied materials.

Material
$\begin{aligned} & \text { Excite/ } \\ & \text { Tetric-Ceram } \\ & \text { highly dispersed silica, ethanol, catalysts and stabilizers. Resin: Bis-GMa, urethane dimethacrylate, } \\ & \text { TEGDMA, barium glass, ytterbium trifluorid, barium-aluminum-fluorosilicate glass, } \\ & \text { high dispersed silica, additives, catalysts and stabilizers, pigments }\end{aligned}$
Pitremer
Primer: HEMA, methacrylated polycarboxylic acids, water, ethanol, photoinitiator.


blast was applied to favor evaporation of the alcohol solvent, and primer adhesive was light-cured for 20 $\mathrm{s}$, according to the manufacturer's instructions. Tetric Ceram resin composite was inserted using a minimum of two increments. Each increment was light cured for $40 \mathrm{~s}$ using a visible light-curing device (XL 3000, 3M ESPE) at $600 \mathrm{~mW} / \mathrm{cm}^{2}$, as monitored periodically by a curing radiometer (Demetron Research Corporation; SDS Kerr, Orange, CA, USA).

Vitremer: Primer was applied using a microbrush on the surface of the lesion for $30 \mathrm{~s}$ and then light-cured for $20 \mathrm{~s}$. The RMGIC was mixed at a powder/liquid ratio of 1:1 in a glass plate with a \#24 spatula. The material was inserted using Centrix-type syringe with disposable tips, and light-cured for $40 \mathrm{~s}$. Removal of excess material was immediately done with a \#12 blade. Finishing and polishing were performed 1 week later using 12-fluted tungsten carbide urs (Jet Burs, São Paulo, SP, Brazil), abrasive cups (Enhance; Dentsply Caulk, Milford, DE,
USA) and polishing disks (Sof-Lex; 3M ESPE).

\section{Clinical Evaluation}

Two independent, calibrated examiners, other than the operator, evaluated all restorations in a doubleblind study design. Modified USPHS criteria (10) were used to evaluate retention, marginal integrity, marginal discoloration, anatomic form and secondary caries (Table 2) at baseline, 6, 12 and 24 months. The baseline rating was carried out immediately after finishing and polishing procedures.

\section{Statistical Analysis}

The obtained data were tabulated and differences between restorative materials at each period were analyzed by the Fisher's exact test or the Pearson's chi-square at $5 \%$ significance level. Inter-examiner

Table 2. Modified USPHS criteria rating system.

\begin{tabular}{|c|c|c|c|}
\hline \multirow{2}{*}{ Category } & \multicolumn{2}{|c|}{ Rating scale } & \multirow{2}{*}{ Criteria } \\
\hline & Acceptable & Unacceptable & \\
\hline \multirow{2}{*}{ Retention } & Alpha (A) & -- & Restoration is present \\
\hline & -- & Charlie (C) & Restorations is partially or totally lost \\
\hline \multirow{4}{*}{$\begin{array}{l}\text { Marginal } \\
\text { integrity }\end{array}$} & Alpha (A) & -- & No visible gap in which the explorer will penetrate \\
\hline & Bravo (B) & -- & There is visible gap, the explorer will penetrate or catch \\
\hline & -- & Charlie (C) & The explorer penetrates the gap and dentin or base is exposed \\
\hline & -- & Delta (D) & The restoration is mobile, partially or totally fractured or lost \\
\hline \multirow{3}{*}{$\begin{array}{l}\text { Marginal } \\
\text { discoloration }\end{array}$} & Alpha (A) & -- & No discoloration \\
\hline & Bravo (B) & -- & Discoloration is present but has not penetrated along the margin \\
\hline & -- & Charlie (C) & Discoloration has penetrated along the margin \\
\hline \multirow{3}{*}{$\begin{array}{l}\text { Anatomic } \\
\text { form }\end{array}$} & Alpha (A) & -- & Restoration is continuous with existing anatomic form \\
\hline & Bravo (B) & -- & $\begin{array}{l}\text { Restoration is discontinuous with existing anatomic form, } \\
\text { but dentin or base is not exposed }\end{array}$ \\
\hline & -- & Charlie (C) & Sufficient material is lost to expose dentin or base \\
\hline \multirow{2}{*}{$\begin{array}{l}\text { Secondary } \\
\text { caries }\end{array}$} & Alpha (A) & -- & No caries is present at the margin of the restoration \\
\hline & -- & Charlie (C) & There is evidence of caries at the margin of the restoration \\
\hline
\end{tabular}


agreement was assessed using kappa. For all criteria, excellent agreement was registered between both examiners (retention: kappa $=1.00$; marginal integrity: kappa $=0.95$; marginal discoloration: $k a p p a=0.85$; secondary caries: kappa $=1.00$ ). Intra-group comparisons between baseline and 2-year evaluation within the same material were performed by McNemar test $(\alpha=0.05)$.

\section{RESULTS}

The overall recall rate was $93.3 \%$ at 2 years ( 59 restorations out of 70). From the 30 patients, 2 could not be reassessed (4 restorations) because one patient moved and one died during the follow-up. Another 7 composite restorations were replaced during the study time for lost, while no ionomer restoration was lost.

A 78.8\% retention rate was recorded for Excite/ Tetric Ceram $(p=0.011)$ at the 2-year recall, with 7 restorations lost. Vitremer had $100 \%$ retention rate.

Table 3 presents data for retention, marginal integrity, marginal discoloration, anatomic form and secondary caries for baseline, 6 months, 1 year and 2 years. There was significant differences for Excite/ Tetric Ceram between baseline and 2-year recall for retention $(\mathrm{p}=0.02)$, marginal integrity $(\mathrm{p}=0.002)$ and wear $(p=0.04)$. For Vitremer, significant difference was identified for marginal integrity $(\mathrm{p}=0.001)$.

\section{DISCUSSION}

NCCL are commonly encountered and raise considerable restorative challenges for the dentist. Esthetic Class V materials are generally classified as resin-based composite, conventional and RMGICs, and compomers (6). Moreover, the choice of the restorative product is a critical factor for restorative success.

Table 3. Summary of direct evaluations.

\begin{tabular}{|c|c|c|c|c|c|}
\hline \multirow{2}{*}{ Category } & \multirow{2}{*}{ Material } & Baseline & 6 months & 1 year & 2 years \\
\hline & & $\% A+B$ & $\% A+B$ & $\% A+B$ & $\% A+B$ \\
\hline \multirow{3}{*}{ Retention } & \multirow{3}{*}{$\begin{array}{l}\text { ARC } \\
\text { RMGI }\end{array}$} & $100 \%(35 / 35)$ & $89 \%(31 / 31)$ & $85.7 \%(30 / 35)$ & $78.8 \%(26 / 33)$ \\
\hline & & $100 \%(35 / 35)$ & $100 \%(35 / 35)$ & $100 \%(35 / 35)$ & $100 \%(33 / 33)$ \\
\hline & & $\mathrm{p}=1.00$ & $\mathrm{p}=0.11$ & $\mathrm{p}=0.054$ & $\mathrm{p}=0.011^{*}$ \\
\hline \multirow{3}{*}{$\begin{array}{l}\text { Marginal } \\
\text { integrity }\end{array}$} & \multirow{3}{*}{$\begin{array}{l}\text { ARC } \\
\text { RMGI }\end{array}$} & $97.2 \%(34 / 35)$ & $100 \%(31 / 31)$ & $100 \%(30 / 30)$ & $100 \%(26 / 26)$ \\
\hline & & $100 \%(35 / 35)$ & $100 \%(35 / 35)$ & $100 \%(35 / 35)$ & $100 \%(33 / 33)$ \\
\hline & & $\mathrm{p}=1.00$ & $\mathrm{p}=1.00$ & $\mathrm{p}=1.00$ & $\mathrm{p}=1.00$ \\
\hline \multirow{3}{*}{$\begin{array}{l}\text { Marginal } \\
\text { discoloration }\end{array}$} & \multirow{3}{*}{$\begin{array}{l}\text { ARC } \\
\text { RMGI }\end{array}$} & $100 \%(35 / 35)$ & $100 \%(31 / 31)$ & $100 \%(30 / 30)$ & $100 \%(26 / 26)$ \\
\hline & & $100 \%(35 / 35)$ & $100 \%(35 / 35)$ & $100 \%(35 / 35)$ & $100 \%(33 / 33)$ \\
\hline & & $\mathrm{p}=1.00$ & $\mathrm{p}=1.00$ & $\mathrm{p}=1.00$ & $\mathrm{p}=1.00$ \\
\hline \multirow{3}{*}{$\begin{array}{l}\text { Anatomic } \\
\text { form }\end{array}$} & \multirow{3}{*}{$\begin{array}{l}\text { ARC } \\
\text { RMGI }\end{array}$} & $100 \%(35 / 35)$ & $97 \%(31 / 31)$ & $96.6 \%(29 / 30)$ & $96.2 \%(25 / 26)$ \\
\hline & & $100 \%(35 / 35)$ & $100 \%(35 / 35)$ & $100 \%(35 / 35)$ & $100 \%(33 / 33)$ \\
\hline & & $\mathrm{p}=1.00$ & $\mathrm{p}=0.09$ & $\mathrm{p}=0.462$ & $\mathrm{p}=0.441$ \\
\hline \multirow{3}{*}{$\begin{array}{l}\text { Secondary } \\
\text { caries }\end{array}$} & \multirow{3}{*}{$\begin{array}{l}\text { ARC } \\
\text { RMGI }\end{array}$} & $100 \%(35 / 35)$ & $100 \%(31 / 31)$ & $100 \%(30 / 30)$ & $100 \%(26 / 26)$ \\
\hline & & $100 \%(35 / 35)$ & $100 \%(35 / 35)$ & $100 \%(35 / 35)$ & $100 \%(33 / 33)$ \\
\hline & & $\mathrm{p}=1.00$ & $\mathrm{p}=1.00$ & $\mathrm{p}=1.00$ & $\mathrm{p}=1.00$ \\
\hline
\end{tabular}

$\mathrm{ARC}=$ adhesive system $/$ resin composite $($ Excite/Tetric Ceram $) ; \mathrm{RMGIC}=$ resin-modified glass ionomer cement $($ Vitremer $) ;{ }^{*}$ Indicates significant differences between the tested materials for that criterion. 
Clinical retention effectiveness of restorations is best evaluated in class- $\mathrm{V}$ studies because cervical lesions do not provide any macro-mechanical retention, so that ineffective bonding will result in early loss of the restorations (11). Several researchers have used this experimental model to assess the clinical performance of materials placed in NCCL $(1,3,4-8,10-14)$.

In this study, the one-bottle etch-and-rinse adhesive and resin composite system (Excite/Tetric Ceram) showed a $78.8 \%$ retention rate after 2 years. One reason might be the fact that NCCL have a non-retentive cavity shape and margins lying on dentin or cementum, which are unfavorable for bonding. Similarly, clinical trials have reported alpha rates for retention of $88 \%$ for One-Step/Silux at 2 years (3). Kubo et al. (15) evaluated the performance of a one-bottle adhesive system after 5 years and found excellent retention rates (100\%); however, these authors prepared an enamel bevel that could be enhance the retention. More recently, Kubo et al. (13) reported $98 \%$ retention rates for one-bottle self-etch systems after 2-year recall using enamel bevel preparation. According to a recent review article (16), clinical monitoring of adhesive/resin composite restorations placed on cervical lesions reveals different results, with retention rates ranging from 51 to $100 \%$ after 3 years of evaluation in teeth without an enamel bevel, and $100 \%$ after 5 years when an enamel bevel is prepared. Nevertheless, further studies are necessary, since others have reported no effect of enamel beveling on the retention rates of NCCL restorations $(4,6)$.

The retention rate for the RMGIC restorations in the present study was of $100 \%$. The high retention rate of Vitremer may be attributed to its capacity of adhering to enamel and dentin. The excellent clinical data definitely confirm the self-adhesive property of GICs. This self-adhesiveness must be ascribed to combined micro-mechanical interlocking and chemical interaction. The micro-mechanical bonding component has been suggested to provide in particular resistance to abrupt de-bonding stress, while the chemical interaction may result in bonds that better resist hydrolytic breakdown (17). Similarly, Chinelatti et al. (12) found no loss of restorations using Vitremer after 1 year. Burgess et al. (6), after 3 years showed retention rate of $90 \%$ to RMGI (Fuji II LC Improved) and van Dijken (7) using a RMGIC adhesive (Fuji Bond LC) found a lost of $4.5 \%$ and $17.9 \%$ after 2 and 6 years, respectively. Recently, van Dijken and Pallesen (18), found that the annual failure for Vitremer was of $2.7 \%$.
A challenge to retention is that the etiology of NCCL is multifactorial. Some occur when tooth flexure produces tensile forces, occasioned by impact of tensile stress from mastication and malocclusion. This cyclic tension and compression may reach a fatigue limit and result in cracking or breakage of the restorative materials that may induce to retention failure. This way, the failure of these restorations has been linked to the stiffness of the restorative material. According Bayne et al. (19), the elasticity modulus is an important property in the retention of restorations placed in NCCL. When a more rigid composite material such as a hybrid is used the shear stress at the adhesive interface could exceed the compressive stress, thus acting primarily on the bond. The introduction of low modulus resin based materials has been promoted as possibly beneficial for restoring NCCL. However the results are unclear, bringing into question the role of material's stiffness in the retention of NCCL restorations (5).

Another factor to retention failure is the presence of sclerotic dentin in NCCL, which is more resistant to acid demineralization than young dentin, resulting in a thin, variable hybrid layer (3). Therefore, age is a factor that changes the composition and the structure of dentin. Bayne et al. (19) found a greater restoration loss for patients of older age; patients aged 21-40, 41-60 and 6180 years had loss of $31 \%, 62 \%$ and $75 \%$ or restorations, respectively. The occurrence of structural changes of the enamel and dentin resulting from advanced age and the possible correlation between these changes and the longevity of cervical restorations cannot be disregarded; however, failures of retention, cannot not credited only to the type of substrate.

Based on the results, the tested hypothesis could not be accept because the retention of Excite/Tetric Ceram restorations was registered as $78.8 \%$, while the RMGIC restorations had retention rate of $100 \%$. Only the ionomer restorations met the American Dental Association's acceptance guidelines for restorative materials (9), according to which failure rate of restorations cannot be higher than $5 \%$ at 2 years.

As to marginal integrity, Excite/Tetric Ceram reported $50 \%$ of rated "B", this could be associated with shrinkage that occurs during polymerization of the resin-based composite (6). Problems at tooth/restoration interface as marginal integrity and marginal discoloration are associated with physical, mechanical and viscoelastic proprieties of materials. The difference in the coefficient of thermal expansion between the tooth and restorative 
material leads to percolation and consequently marginal alterations, and produces interfacial tensions due to repeated temperature changes, which, allied to those created during polymerization shrinkage, result in marginal infiltration and discoloration. Ichim et al. (20) determined that during the masticatory stresses, prior to fracture, a restorative material undergoes strain softening that is a consequence of the accumulation of microcracks. This strain softening induces the action of chemical and mechanical degradation. However, in this study, the materials showed similar behavior in integrity and marginal discoloration, despite having different thermal expansion coefficients. For light-cured restorative materials in particular, polymerization shrinkage tends to generate contraction stresses at the cavity floor and cause deterioration of the adaptation (12).

The overall superior behavior of RMGIC restorations compared to other materials has been demonstrated in previous short- $(1,6,12)$ and long-term evaluations (18).

In conclusion, in the present controlled clinical trial, the RMGIC Vitremer showed a superior clinical effectiveness compared to the combination of a onebottle adhesive system and a hybrid resin composite (Excite/TC) after 2 years of follow up. However, the results of this study must be substantiated by a longer period of observation.

\section{RESUMO}

Esse estudo avaliou o desempenho clínico de restaurações de lesões cervicais não-cariosas por um período de 2 anos empregando um sistema adesivo de condicionamento total (Excite/Tetric Ceram) e um cimento de ionômero de vidro modificado por resina (Vitremer). Setenta restaurações (35 por material) foram realizadas por um único operador. Todas as lesões cervicais nãocariosas foram restauradas sem a execução de preparo cavitário e sob isolamento absoluto. As restaurações foram avaliadas por 2 examinadores independentes usando os critérios USPHS modificados nos períodos inicial, 6, 12 e 24 meses. A análise estatística foi realizada pelos testes de Fisher e McNemar. Cinquenta e nove restaurações foram avaliadas após 2 anos, obtendo-se um índice de retenção de 78,8\% para resina composta e $100 \%$ para o cimento de ionômero de vidro modificado por resina. O teste exato de Fischer detectou diferença significante $(p=0,011)$ para retenção entre os dois materiais. Contudo, não houve diferença significante para integridade marginal, descoloração marginal, forma anatômica e cárie secundária. O teste de $\mathrm{McNemar}$ detectou diferença estatística para o sistema Excite/Tetric Ceram entre o período inicial e 2 anos para os critérios de retenção $(\mathrm{p}=0,02)$, integridade marginal $(\mathrm{p}=0,002)$ e forma anatômica $(\mathrm{p}=0,04)$. Portanto, o sistema adesivo de condicionamento total apresentou um desempenho clínico inferior comparado ao cimento de ionômero de vidro modificado por resina.

\section{REFERENCES}

1. Santiago SL, Franco EB, Mendonça JS, Lauris JRP, Navarro MFL. One-year clinical evaluation of tooth-colored materials in noncarious cervical lesions. J Appl Oral Sci 2003;11:175-180.

2. Franco EB, Benetti AR, Ishikiriama SK, Santiago SL, Lauris JRP, Jorge MFF, et al.. Five-year clinical performance of resin composite versus resin modified glass ionomer restorative system in non-carious cervical lesions. Oper Dent 2006;31:403-408.

3. Tyas MJ, Burrow MF. Three-year clinical evaluation of one-step in non-carious cervical lesions. Am J Dent 2002;15:309-311.

4. Belluz M, Pedrocca M, Gagliani M. Restorative treatment of cervical lesions with resin composites: 4-year results. Am J Dent 2005; 18:307-310.

5. Browning WD, Brackett WW, Gilpatrick RO. Two-year clinical comparison of a microfilled and a hybrid resin-based composite in non-carious class V lesions. Oper Dent 2000;25:46-50.

6. Burguess JO, Gallo JR, Ripps AH, Walker RS, Ireland EJ. Clinical evaluation of four class 5 restorative materials: 3 -year recall. Am J Dent 2004; 17:147-150.

7. Van Dijken JWV. Retention of a resin modified glass ionomer adhesive in non-carious cervical lesions. A 6-year follow-up. J Dent 2005;33:541-547.

8. Neo J, Chew CL, Yap A, Sidhu S. Clinical evaluation of tooth colored materials in cervical lesions. Am J Dent 1996;9:15-18.

9. American Dental Association. Council on scientific affairs. Acceptance program guidelines. Rest Mater 1996;1-9.

10. Ryge G. Clinical criteria. Int Dent J 1980;30:347-358.

11. Peumans M, De Munck J, Van Landuyt KL Van, Kanumilli P, Yoshida Y, Inoue S, et al.. Restoring cervical lesions with flexible composites. Dent Mater 2007;23:749-754.

12. Chinelatti MA, Ramos RP, Chimello DT, Palma-Dibb RG. Clinical performance of a resin-modified glass-ionomer and two polyacidmodified resin composites in cervical lesions restorations: 1-year follow-up. J Oral Rehabil 2004;31:251-257.

13. Kubo S, Yokota H, Yokota H, Hayashi Y. Two-year clinical evaluation of one-step self-etch systems in non-carious cervical lesion. J Dent 2009;37:149-155.

14. Ozel E, Say EC, Yurdaguven H, Soyman M. One-year clinical evaluation of a two-step self-etch adhesive with and without additional enamel etching technique in cervical lesions. Aust Dent J 2010;55:156-161.

15. Kubo S, Kawasaki K, Yokota H, Hayashi Y. Five-year clinical evaluation of two adhesive systems in non-carious cervical lesions. J Dent 2006;34:97-105.

16. Santiago SL, Vieira AHM, Passos VF. Restorations of non-carious cervical lesions: problems and solutions. Pro-Odonto Estética 2008;1:83-138. (in Portuguese)

17. Peumans M, Kanamulli P, De Munck J, Van Landuyt K. Clinical effectiveness of contemporary adhesives: A systematic review of current clinical trials. Dent Mater 2005;21:864-881.

18. van Dijken JW, Pallesen U. Long-term dentin retention of etchand-rinse and self-etch adhesives and a resin-modified glass ionomer cementin non-carious cervical lesions. Dent Mater 2008;24:915-922.

19. Bayne SC, Heymann HO, Sturdevant JR, Wilder AD, Sluder TB. Contributing co-variables in clinical trials. Am J Dent 1991;4:247-250.

20. Ichim IP, Schmidlin PR, Li Q, Kieser JA, Swain MV. Restoration of non-carious cervical lesions Part II. Restorative material selection to minimize fracture. Dent Mater 2007;23:1562-1569.

Accepted June 11, 2010 